\title{
CONSEJOS CONSULTIVOS AUTONÓMICOS Y ADMINISTRACIÓN LOCAL
}

\author{
POR \\ JOAN OLIVER ARAUJO \\ Catedrático de Universidad de Derecho Constitucional \\ Consejero del Consejo Consultivo de las Islas Baleares
}

\section{LA FUNCIÓN ASESORA DE LOS CONSEJOS CONSULTIVOS AUTONÓMICOS: ORIGEN, NATURALEZA JURÍDICA Y SIGNIFICADO}

El objeto básico de este trabajo, como indica el título que lo preside, lo constituye el análisis de las competencias de los consejos consultivos autonómicos en materias propias de las Administraciones locales. Ello nos obliga a estudiar, aunque sea de forma necesariamente somera, el origen, la naturaleza jurídica y el significado de estos órganos autonómicos de consulta.

Los órganos de la Administración con competencias resolutorias, es decir, los órganos de la Administración activa, necesitan del apoyo técnico de otros órganos para preparar sus decisiones; desarrollándose, de esta manera, la actividad consultiva a través de procedimientos y técnicas de diversa naturaleza (Ramón Parada). Como ha señalado el profesor Carlos Ruiz Miguel, el Consejo de Estado y los consejos consultivos autonómicos tienen cuatro notas comunes que los caracterizan: se trata de órganos institucionalizados; se trata de órganos colegiados; "tienen competencia general y no circunscrita a un determinado sector" (si bien en el caso de los órganos de consulta autonómicos su labor está circunscrita al territorio de la respectiva Comunidad Autónoma); y, finalmente, se trata de cuerpos técnicos y no de tipo representativo-participativo. 
Es cierto que existen muchos otros órganos consultivos, incluso materialmente muy importantes (vg. los órganos del Estado Mayor de la Administración Militar, los Gabinetes Jurídicos de los diferentes Departamentos Ministeriales y, muy especialmente, el Gabinete del Presidente del Gobierno), pero nuestro estudio se va a circunscribir a aquellos órganos que reúnen las cuatro características apuntadas.

La estructura consultiva colegial que nosotros vamos a analizar implica "un cierto distanciamiento entre el órgano consultado y el asistido, que se comunican a través de un procedimiento formalizado. La petición de la consulta y el dictamen resultante se producen por escrito, incorporándose al expediente o procedimiento en que se han producido. La razón de este formalismo hay que verla en el hecho de que estos órganos cumplen, a la vez que una función asesora, una cierta función de garantía respecto de los administrados" (Ramón Parada).

En esta introducción al tema que nos ocupa, debemos afirmar que, pese a los autores que consideran al Consejo de Estado como un órgano innecesario (así, por ejemplo, el profesor Santamaría Pastor), es lo cierto que la Constitución de 1978 lo consagró de forma expresa en el artículo 107 y que la Ley Orgánica del Consejo de Estado de 1980 ha incrementado de forma notable sus funciones tradicionales. De la misma manera, los consejos consultivos autonómicos, creados en buena medida sobre el modelo del Consejo de Estado, han adquirido un auge extraordinario en los últimos trece años. Analizaremos, a continuación, cómo y por qué se ha producido esta afloración de órganos autonómicos consultivos.

El art. 23.2 de la Ley Orgánica del Consejo de Estado (LOCE) dispone que el dictamen del Consejo de Estado será preceptivo para las Comunidades Autónomas "en los mismos casos previstos en esta Ley para el Estado, cuando hayan asumido las competencias correspondientes". La posible inconstitucionalidad de este precepto provocó, en su momento, un fuerte debate doctrinal, sólo apaciguado con la intervención clarificadora del «intérprete supremo de la Constitución». En efecto, el Tribunal Constitucional, en la Sentencia 204/1992, de 26 de noviembre, se pronunció sobre la constitucionalidad del artículo 23.2 de la LOCE, a raíz de la cuestión de inconstitucionalidad planteada por la Sala de lo Contencioso-Administrativo del Tribunal Superior de Justicia de la Comunidad Valenciana. Por su extraordinaria importancia, recordaremos los aspectos más relevantes de esta resolución.

El Tribunal Constitucional comienza su razonamiento examinando, in genere, si el precepto contenido en el segundo apartado del artículo 23 de la LOCE es o no conforme con la Constitución y, más en concreto, 
con su artículo 107 («El Consejo de Estado es el supremo órgano consultivo del Gobierno") y con la autonomía de las nacionalidades y regiones en ella garantizada. Tras las oportunas consideraciones jurídicas, el Tribunal llega a una primera conclusión relevante: del artículo 107 "no se puede deducir que la Constitución imponga la intervención consultiva del Consejo de Estado en relación con la actuación de los Gobiernos y Administraciones de las Comunidades Autónomas». Sin embargo, acto seguido, añade: "Ahora bien, que el artículo 107 CE no contemple expresamente sino la función consultiva que el Consejo de Estado desarrolla para el Gobierno de la Nación, no quiere decir que ese órgano haya de quedar confinado al ejercicio de esa específica función y que no pueda extender el alcance de su intervención consultiva. En realidad - sigue diciendo-, el ámbito de actuación del Consejo de Estado es mucho más amplio, y se ha venido configurando históricamente como órgano consultivo de las Administraciones Públicas. El hecho de que no forme parte de la Administración activa, su autonomía orgánica y funcional, garantía de objetividad e independencia, le habilitan para el cumplimiento de esa tarea, más allá de su condición esencial de órgano consultivo del Gobierno, en relación también con otros órganos gubernativos y con Administraciones Públicas distintas de la del Estado, en los términos que las leyes dispongan, conforme a la Constitución" (fund. juríd. 2..$^{\circ}$. Dicho con otras palabras, el artículo 107 de la Constitución no ha establecido que el Consejo de Estado sea el supremo órgano consultivo de los Gobiernos y las Administraciones de las Comunidades Autónomas, pero tampoco impide que lleve a cabo esta función.

A juicio del Tribunal Constitucional, "la intervención preceptiva de un órgano consultivo de las características del Consejo de Estado, sea o no vinculante, supone en determinados casos una importantísima garantía del interés general y de la legalidad objetiva". Se trata de "una función muy cualificada que permite al legislador elevar su intervención preceptiva, en determinados procedimientos, a la categoría de norma básica del régimen jurídico de las Administraciones Públicas o parte del procedimiento administrativo común (art. 149.1.18 CE). Sin embargo, esta garantía procedimental debe cohonestarse con las competencias que las Comunidades Autónomas han asumido para regular la organización de sus instituciones de autogobierno (art. 148.1.1 CE), de modo que esa garantía procedimental debe respetar al mismo tiempo las posibilidades de organización propia de las Comunidades Autónomas que se deriven del principio de autonomía organizativa (arts. 147.2.c y 148.1.1 CE). Ningún precepto constitucional, y menos aún el que se refiere al Consejo de Estado, impide que en el ejercicio de esa autonomía 
organizativa las Comunidades Autónomas puedan establecer, en su propio ámbito, órganos consultivos equivalentes al Consejo de Estado en cuanto a su organización y competencias, siempre que éstas se ciñan a la esfera de atribuciones y actividades de los respectivos Gobiernos y Administraciones autonómicas» (fund. juríd. 4. ${ }^{\circ}$ ).

En coherencia con lo anterior, «si una Comunidad Autónoma, en virtud de su potestad de autoorganización (art. 148.1.1 CE), crea un órgano superior consultivo semejante, no cabe duda de que puede dotarlo, en relación con las actuaciones del Gobierno y la Administración autonómica, de las mismas facultades que la LOCE atribuye al Consejo de Estado". Además, evitando cualquier posible ambigüedad, el Tribunal Constitucional subraya que la creación de un órgano consultivo autonómico no se superpone al Consejo de Estado, sino que lo sustituye. En efecto, si las Comunidades Autónomas «crean un órgano consultivo propio dotado de las mismas funciones que el Consejo de Estado es, claramente, porque han decidido prestar las garantías procedimentales referidas a través de su propia organización, sustituyendo la que hasta ahora ha venido ofreciendo aquel órgano consultivo estatal también en el ámbito de competencia de las Comunidades Autónomas. Decisión ésa que, según se ha dicho, se encuentra plenamente legitimada por el artículo 148.1.1 de la CE y los preceptos concordantes de los Estatutos de Autonomía. Además habría que añadir que sería probablemente innecesario y, sin duda, gravoso y dilatorio que en un mismo procedimiento debiera recabarse sucesivamente dictamen de un órgano superior consultivo autonómico de características parecidas al Consejo de Estado y del propio Consejo de Estado, con desprecio de los principios de eficacia administrativa (art. 103.1 CE) y eficiencia y economía del gasto público (art. 31.2 CE)». La aplicación de estos principios, básicos para el correcto funcionamiento del Estado autonómico, "debe llevar a concluir que la intervención del órgano consultivo autonómico excluye la del Consejo de Estado" (fund. juríd. 5.).

De acuerdo con todo este razonamiento, el Tribunal Constitucional afirma que, "no sólo hay que reconocer las competencias de las Comunidades Autónomas para crear, en virtud de sus potestades de autoorganización, órganos consultivos propios de las mismas características y con idénticas o semejantes funciones a las del Consejo de Estado, sino, por la misma razón, estimar posible constitucionalmente la sustitución del informe preceptivo de este último por el de un órgano superior consultivo autonómico, en relación al ejercicio de las competencias de la respectiva Comunidad, en tanto que especialidad derivada de su organización propia». Pero, si es preciso reconocer esa posibilidad de sustitución, también es necesario afirmar que en donde seme- 
jantes órganos consultivos autonómicos no existan, es decir, en aqueIlas Comunidades Autónomas "que no cuenten con esta especialidad derivada de su organización propia, las garantías procedimentales mencionadas exigen mantener la intervención preceptiva del Consejo de Estado" (fund. juríd. 5. ${ }^{\circ}$ ).

Esta posibilidad de sustituir el dictamen del Consejo de Estado por el de un consejo consultivo autonómico "equivalente" se ha concretado hasta el día de hoy en quince de las diecisiete Comunidades Autónomas, que - por orden cronológico de aprobación-son las siguientes: Cataluña (que tiene dos: el Consejo Consultivo y la Comisión Jurídica Asesora), Canarias, Baleares (que fue la primera Comunidad Autónoma que lo creó después de la STC 204/92), Andalucía, Valencia, Aragón, La Rioja, Galicia, Castilla-La Mancha, Murcia, Navarra, País Vasco, Extremadura, Castilla y León y Asturias. En consecuencia, sólo hay dos Comunidades Autónomas (Madrid y Cantabria) que, ante la exigencia legal del dictamen de un alto órgano consultivo, tienen que acudir al Consejo de Estado.

El Consejo de Estado y los consejos consultivos autonómicos son órganos con una naturaleza bifronte: órganos consultivos y órganos de control. Veamos ambas dimensiones.

1. Como órganos consultivos colaboran con la Administración activa para que sus decisiones sean conformes al ordenamiento jurídico. Son una voz técnicamente autorizada y socialmente prestigiosa que quiere ayudar al Gobierno y a las Administraciones Públicas (incluida, obviamente, la Administración local) a acertar en la toma de decisiones. La labor consultiva se expresa como una actividad auxiliar que implica emitir juicios sobre cuestiones sometidas a examen (Gálvez Montes), para que el órgano decisorio pueda formar su criterio con más elementos de juicio. Como señala el profesor José Antonio González Casanova, los órganos consultivos ayudan a los órganos políticos y a las Administraciones Públicas a tomar decisiones "con el mayor conocimiento de causa, el máximo rigor ético y toda la prudencia que la audacia exija".

2. Sin embargo, como señala la doctrina mayoritaria (por todos, pueden verse Eduardo Vírgala, Antonio Pérez-Tenessa y Antonio López Pina), también son órganos de control. Aspecto que se acentúa si se contemplan los datos de su independencia funcional y de su intervención preceptiva en numerosos supuestos. La intervención del Consejo de Estado y de los consejos consultivos autonómicos no parece impuesta sólo por la necesidad "del asesoramiento técnico que sus dictámenes puedan comportar, sino con una finalidad cuasi-fiscalizadora, 
orientada a que el Gobierno y la Administración sigan en esas materias el parecer del órgano consultado, so pena de que sus actuaciones, o bien no sean válidas, si se omite la petición del informe, o sufran una cierta desautorización material si el Gobierno o la respectiva Administración deciden en contra de la opinión de aquél» (Ramón Parada). El profesor Tomás de la Quadra-Salcedo lo ha expresado de forma muy clara: "La presencia de un órgano consultivo tiene una profunda dimensión de control: el control que supone el no poder hacer algo sin oír el parecer de alguien". Además, cuando el dictamen del órgano consultado no sólo es preceptivo, sino también vinculante (por ejemplo, para la modificación de zonas verdes en los municipios), es evidente que se convierte en cotitular de la competencia, pues su criterio negativo impide a la Administración activa seguir adelante.

Precisamente para poder cumplir con esta función de control, se les reviste de importantes garantías («ejercen la función consultiva con autonomía orgánica y funcional para garantizar su objetividad e independencia»), y se les encomienda un cometido objetivo ("velar por la observancia de la Constitución y del resto del ordenamiento jurídico»). El control que ejerce el Consejo de Estado y los consejos consultivos autonómicos es fundamentalmente de legalidad, pero también podrá ser de oportunidad y conveniencia cuando lo pida expresamente la autoridad consultante o cuando lo permita su normativa específica.

Los dictámenes del Consejo de Estado y de los consejos consultivos autonómicos no son vinculantes, salvo que una ley disponga lo contrario. Los asuntos en los que hubieran dictaminado no podrán remitirse a informe de ningún otro cuerpo u órgano de la Administración, como consecuencia del carácter de "superior» que la Constitución o los Estatutos de Autonomía les confieren. Las disposiciones y resoluciones sobre asuntos informados por el Consejo de Estado o los consejos consultivos autonómicos expresarán si se adoptan conforme con el dictamen emitido o se apartan de él (en el primer caso se usará la fórmula "de acuerdo"; en el segundo, la de "oído").

Para terminar esta primera parte de mi trabajo, y sintetizando ideas anteriores, quiero decir que la razón de ser del Consejo de Estado y de los consejos consultivos autonómicos estriba en que tanto el Gobierno como las Administraciones Públicas para poder adoptar ciertas resoluciones o dictar determinadas disposiciones especialmente importantes precisan, obligatoriamente, pedir la opinión - esto es, el dictamen- de un órgano jurídico altamente cualificado e independiente. Luego, el órgano consultante podrá hacerle caso o no, ya que su criterio casi nun- 
ca es vinculante, pero en este último caso deberá indicar expresamente que se aparta de aquel dictamen, lo cual podrá suponerle una cierta desautorización jurídica.

\section{LAS COMPETENCIAS DE LOS ÓRGANOS CONSULTIVOS AUTONÓMICOS EN MATERIA LOCAL}

\subsection{Introducción}

Por lo que se refiere a las competencias de los órganos consultivos autonómicos (y dejando a parte el Consejo Consultivo de la Generalitat de Cataluña que, en realidad, no asume los cometidos propios del Consejo de Estado, sino que actúa como un tribunal constitucional preventivo siguiendo el modelo del Consejo Constitucional francés), podemos clasificar los consejos consultivos en dos grupos:

- Primer grupo. Aquéllos órganos autonómicos de consulta que se limitan a asumir, en su propio ámbito territorial, los mismos cometidos que antes correspondían al Consejo de Estado. En este grupo incluiríamos, entre otros, al Consejo Consultivo de las Islas Baleares, a la Comisión Jurídica Asesora de Cataluña, a la Comisión Jurídica Asesora del Gobierno de Aragón y al Consejo Consultivo de la Rioja.

- Segundo grupo. Aquellos consejos consultivos autonómicos que, además de las competencias del Consejo de Estado en su territorio, han asumido el control preventivo de la constitucionalidad y de la estatutoriedad de los anteproyectos de ley que se someten al Parlamento autonómico. Este modelo es el seguido, entre otros, por los consejos consultivos de Canarias, Andalucía, Valencia y Asturias.

Haciendo un rápido recorrido a los listados competenciales de los quince Consejos Consultivos que actualmente están en funcionamiento, podemos concluir que las Administraciones locales requieren dictamen preceptivo de los mismos en las siguientes materias:

1. Conflictos en defensa de la autonomía local planteados por las entidades locales de una Comunidad Autónoma ante el Tribunal Constitucional.

2. Responsabilidad patrimonial derivada de las reclamaciones de indemnización por daños y perjuicios formuladas ante las corporaciones locales.

3. Revisión de oficio de los actos de las corporaciones locales. 
4. Interpretación, modificación, resolución y anulación de concesiones y contratos de las Administraciones locales.

5. Modificación de instrumentos de planeamiento urbanístico cuando tengan por objeto establecer, de manera diferente, la zonificación o uso de las zonas verdes o los espacios libres.

6. Segregación de municipios.

7. Recurso extraordinario de revisión.

A continuación, nos detendremos brevemente en el análisis de estos siete grupos de competencias de los entes locales que, antes de ser ejercidas, requieren, preceptivamente, el dictamen del correspondiente consejo consultivo autonómico.

\subsection{Conflictos en defensa de la autonomía local planteados por las entidades locales de una Comunidad Autónoma ante el Tribunal Constitucional}

La Ley Orgánica 7/1999, de 21 de abril, encomendó un nuevo cometido al Tribunal Constitucional: el conocimiento de los llamados "conflictos en defensa de la autonomía local». Esta competencia (que se ha enmarcado en los nuevos artículos 75 bis, 75 ter, 75 quarter y 75 quinque de la Ley Orgánica del Tribunal Constitucional de 1979) «se concreta en la creación de un nuevo proceso constitucional" para defender la autonomía de los entes locales frente al legislador (Gómez Montoro). La autonomía local, como es obvio, se refiere a la autonomía administrativa y está garantizada en los artículos 141 y 142 de la Constitución).

En base a esta competencia los municipios, islas y provincias casi siempre de forma agrupada, aunque excepcionalmente de forma individual, pueden impugnar ante el Tribunal Constitucional las leyes y normas con rango de ley del Estado y de las Comunidades Autónomas que lesionen la autonomía local constitucionalmente garantizada. Pues bien, las entidades locales en número suficiente para plantear el conflicto, y previamente, a la formalización del mismo, deben solicitar, en el plazo de tres meses desde la publicación de la ley que se entiende que lesiona la autonomía local, dictamen preceptivo y no vinculante del Consejo de Estado o del órgano consultivo de la Comunidad Autónoma si lo hubiere, según que el ámbito territorial al que pertenezcan las corporaciones locales corresponda a varias o a una Comunidad Autónoma. En las Comunidades que no dispongan de consejo consultivo propio, el dictamen lo emitirá el Consejo de Estado. 
Como dato anecdótico, podemos destacar que el primer conflicto en defensa de la autonomía local que se interpuso ante el Tribunal Constitucional tuvo su origen en una acción conjunta de doce Ayuntamientos de Baleares que, por esta vía, atacaron una Ley del Gobierno autonómico que excluía la licencia municipal de obras en la aprobación de planes territoriales parciales y planes directores sectoriales. El Consejo Consultivo de las Isla Baleares informó favorablemente el planteamiento de este conflicto en defensa de la autonomía local, que efectivamente se suscitó por los indicados Ayuntamientos dentro del mes siguiente a la notificación de nuestro dictamen.

\subsection{Responsabilidad patrimonial derivada de las reclamaciones de indemnización por daños y perjuicios formuladas ante las corporaciones locales}

El conocimiento de las peticiones de indemnización de daños y perjuicios por el deficiente funcionamiento de los servicios municipales es, desde un punto de vista cuantitativo, el principal motivo de solicitud de dictámenes a los consejos consultivos por parte de los Ayuntamientos. De hecho, todas las leyes reguladoras de los órganos consultivos autonómicos prevén su dictamen preceptivo en las reclamaciones por responsabilidad patrimonial interpuestas ante la Administración local. La diferencia principal estriba en que, en algunos ordenamientos, se establece una cuantía mínima solicitada para que el expediente tenga que someterse al dictamen del consejo consultivo (por ejemplo $\mathrm{Na}$ varra en donde se exigen 120.202,42 euros, o Baleares donde se exigen 3.000 euros) y, en cambio, en otras Comunidades Autónomas no hay mínimo exento, por lo tanto, sea cual sea la cantidad reclamada, el expediente siempre exige pronunciamiento previo del órgano autonómico de consulta.

Ambas opciones tienen argumentos a favor y en contra. En efecto, exigir una cuantía mínima para que el asunto llegue al consejo consultivo evita que dicho órgano tenga que enredarse en multitud de asuntos mínimos, en los que resulta mucho más costosos la elaboración del dictamen que la cantidad reclamada; de esta manera, se dice, el consejo puede dedicar sus mayores esfuerzos a los cometidos que, bien por su naturaleza bien por su cuantía, resultan más relevantes. Sin embargo, desde otra perspectiva, puede afirmarse que estas pequeñas reclamaciones son las que, precisamente por su escaso montante, nunca llegaran al conocimiento de los jueces de lo contencioso-administrativo, porque el particular afectado sabe perfectamente que los costes 
de un abogado y un procurador superan la hipotética indemnización que pudiera llegar a obtener al final del proceso. Por ello, en estos casos, otorgarle al ciudadano lesionado una opinión jurídica e imparcial de un consejo consultivo puede ser una importante garantía sin coste económico para él. Como decía antes, establecer un montante mínimo para que los asuntos puedan llegar al consejo consultivo, es una decisión que el legislador autonómico debe ponderar cuidadosamente. Sin que, a mi juicio, existan argumentos indiscutibles a favor de una $u$ otra opción.

En los supuestos en que las Administraciones locales solicitan dictamen a los consejos consultivos ante reclamaciones por responsabilidad patrimonial, estos altos órganos de consulta deben comprobar la condición de interesado del reclamante, de conformidad con lo establecido en el artículo 106.2 de la Constitución en relación con el artículo 31 de la Ley 30/92, de 26 de noviembre, de Régimen Jurídico de las Administraciones Públicas y del Procedimiento Administrativo Común (LRJAP-PAC). La reclamación se debe presentar ante el Ayuntamiento presunto responsable del perjuicio económico causado al reclamante; y la competencia para resolver el expediente corresponde al Alcalde, en virtud de la atribución residual de competencias contenida en el artículo 21.s de la Ley 7/1985, de 2 de abril, y en el artículo 41.27 del Real Decreto 2.568/1986, de 28 de noviembre, según los cuales los presidentes de las corporaciones locales ostentan aquellas competencias que las leyes asignen al municipio y no atribuyan a otros órganos municipales.

Con respecto al procedimiento seguido, los consejos consultivos han de comprobar que se ha dado cumplimiento a los trámites exigidos por la LRJAP-PAC y por el Real Decreto 429/1993, de 26 de marzo, por el que se aprueba el Reglamento de los procedimientos en materia de responsabilidad de las Administraciones Públicas; en especial, que se ha concedido de forma efectiva el fundamental trámite de audiencia, tanto en las diferentes fases de la instrucción como una vez culminada la tramitación del procedimiento y antes de la propuesta de resolución. Asimismo, corresponde a los órganos consultivos comprobar la temporaneidad de la reclamación, esto es, que se ha planteado dentro del plazo que marca el artículo 145.2 de la tantas veces citada LRJAP-PAC, que establece que, "en todo caso, el derecho de reclamar prescribe al año de producirse el hecho o el acto que motive la indemnización o de manifestarse su efecto lesivo".

La doctrina de la responsabilidad objetiva de las Administraciones Públicas fue recogida en el artículo 106.2 de la Constitución Española y tiene actualmente su traducción positiva en el artículo 139 y siguientes 
de la Ley 30/1992. Estos preceptos reiteran y acentúan, con respecto a la legislación anterior, el carácter objetivo de dicha responsabilidad. Constante y unánime jurisprudencia del Tribunal Supremo exige, para que haya lugar a la apreciación de este tipo de responsabilidades, la concurrencia de los siguientes elementos intervinientes: la efectiva realidad del daño o perjuicio causado, evaluable económicamente e individualizado con respecto a una persona o grupo de personas; que el daño o lesión sufrido por el reclamante sea consecuencia del funcionamiento normal o anormal de los servicios públicos en una relación directa, inmediata y exclusiva de causa efecto, sin intervención de elementos extraños que puedan influir, alterando el nexo causal; ausencia de fuerza mayor; y que el reclamante no tenga el deber jurídico de soportar el daño.

\subsection{Revisión de oficio de los actos de las corporaciones locales}

Nuestro ordenamiento jurídico-administrativo recoge el principio tradicional de que los actos propios declarativos de derechos subjetivos sólo pueden ser objeto de revisión acudiendo a los procedimientos previstos para ello, ya que la rectificación por la Administración de un error de derecho no puede ser considerada válida de cualquier manera por razones de seguridad jurídica (art. 9.3 CE), en virtud del principio general prohibitivo "venire contra factum propium non valet». Por otra parte, el principio de conservación de los actos administrativos, dada la presunción de legitimidad que ostentan, obliga a quien los produce a mantenerlos, sin que pueda dejarlos sin efectos a menos que sea a través de los mecanismos que el ordenamiento jurídico tiene establecido para ello. Los actos administrativos que producen derechos subjetivos sólo pueden ser revocados en los términos, por el procedimiento y por las causas fijadas en la ley (Dictamen del Consejo Consultivo de las Islas Baleares 39/2001, entre muchos otros en el mismo sentido).

El artículo 53 de la Ley 7/1985, de 2 de abril, reguladora de las bases del régimen local, dispone que las corporaciones locales pueden revisar sus actos y acuerdos en los términos y con el alcance que, para la Administración del Estado, se establece en la legislación estatal reguladora del procedimiento administrativo común. Por tanto, resultan ser de aplicación los artículos 102 a 106 de la Ley 30/1992, de Régimen Jurídico de las Administraciones Públicas y del Procedimiento Administrativo Común, y el artículo 218 del Reglamento de Organización, Funcionamiento y Régimen Jurídico de las Entidades Locales (R.D. 2.568/1986, de 28 de noviembre). 
Como es sabido, el citado artículo 102 de la Ley 30/1992 afirma que las Administraciones Públicas, en cualquier momento, por iniciativa propia o a solicitud de interesado, y previo dictamen favorable del Consejo de Estado u órgano consultivo equivalente de la Comunidad Autónoma, si lo hubiere, declararán de oficio la nulidad de los actos administrativos que hayan puesto fin a la vía administrativa o que no hayan sido recurridos en plazo, en los supuestos previstos en el artículo 62.1. Asimismo, en cualquier momento, las Administraciones Públicas de oficio, y previo dictamen favorable del Consejo de Estado u órgano consultivo equivalente de la Comunidad Autónoma si lo hubiere, podrán declarar la nulidad de las disposiciones administrativas en los supuestos previstos en el artículo 62.2. Como vemos, en estos casos, el dictamen del órgano consultivo autonómico no sólo es preceptivo, sino que además debe ser favorable para que la pretendida revisión de oficio pueda seguir adelante. En este sentido, se puede afirma que el dictamen del consejo consultivo es vinculante si fuese contrario a la nulidad; siendo sólo habilitante (permite la revisión, aunque no obliga a ella) en el caso de que sea favorable a la revisión planteada.

\subsection{Interpretación, modificación, resolución y anulación de concesiones y contratos de las Administraciones locales}

Como ha señalado reiteradamente el Consejo Consultivo de Andalucía (ver, por todos, el Dictamen 64/200, de 7 de marzo), "uno de los principios básicos que presiden las relaciones contractuales es el de la invariabilidad de lo pactado por las partes — principio ne varietur-, que tiene su traducción en diversos preceptos de la legislación contractual administrativa. Debe destacarse, con carácter general, el artículo 4 de la Ley de Contratos de las Administraciones Públicas, conforme al cual la Administración podrá concertar los pactos, cláusulas y condiciones que tenga por convenientes — con los límites impuestos por la propia Ley-, y deberá cumplirlos en su propio tenor. No obstante, en determinadas condiciones, la propia legislación contempla la potestad de la Administración de modificar unilateralmente el objeto de los contratos amparados en el Derecho Administrativo; potestad que se suele denominar como ius variandi. Esta potestad, que se afirma con carácter general en el artículo 59.1 de la Ley de Contratos de las Administraciones Públicas, en tanto que excepción al principio de invariabilidad referido, se encuentra reglada en cuanto a su ejercicio, debiendo someterse de forma estricta a las exigencias del interés público y a los precisos límites que, como protección de ese interés, impone la ley». 
La actividad de los consejos consultivos autonómicos en relación con la actividad contractual de las Administraciones locales viene marcada por los artículos 59 y 96 del Texto Refundido de la Ley de Contratos de las Administraciones Públicas (aprobado por el Real Decreto Legislativo 2/2000, de 16 de junio) y por el artículo 109 del Reglamento General de la Ley de Contratos de las Administraciones Públicas (aprobado por Real Decreto 1.098/2001, de 12 de octubre).

De acuerdo con el primero de aquellos preceptos, dentro de los límites y con sujeción a los requisitos y efectos señalados legalmente, el órgano de contratación ostenta la prerrogativa de interpretar los contratos administrativos, resolver las dudas que ofrezca su cumplimiento, modificarlos por razones de interés público, acordar su resolución y determinar los efectos de ésta. Los acuerdos correspondientes pondrán fin a la vía administrativa y serán inmediatamente ejecutivos. Ahora bien, no obstante lo anterior, y según dispone el tercer apartado del mismo precepto, será preceptivo el dictamen del Consejo de Estado u órgano consultivo equivalente de la Comunidad Autónoma respectiva en los casos de:

a) Interpretación, nulidad y resolución, cuando se formule oposición por parte del contratista.

b) Modificaciones del contrato, cuando la cuantía de las mismas, aislada o conjuntamente, sea superior a un veinte por ciento del precio primitivo del contrato y éste sea igual o superior a 6.010.121,04 euros (es decir, 1.000.000.000 de las antiguas pesetas).

\subsection{Modificación de instrumentos de planeamiento urbanístico cuando tengan por objeto establecer, de manera diferente, la zonificación o uso de las zonas verdes o los espacios libres}

Esta competencia de los órganos consultivos autonómicos se fundamenta en el art. 50 del Texto Refundido de la Ley del Suelo de 1976, aún vigente, como consecuencia de la Sentencia del Tribunal Constitucional de 20 de marzo de 1997. En efecto, al igual que el anulado art. 129 del Texto Refundido de 1992, aquel precepto establece la imposibilidad legal de introducir modificaciones del planeamiento que incidan en zonas verdes o espacios libres sin contar con el informe "favorable" del correspondiente alto cuerpo consultivo. Obsérvese que la necesidad de dictamen de los órganos consultivos de las Comunidades Autónomas está circunscrita a las modificaciones de zonas verdes o espacios 
libres que pretendan introducirse en los planes y normas de ordenación urbanística. Y ello es así porque en esta materia, dado el posible conflicto entre los intereses privados (especulativos) y el interés público (de garantizar a todos los ciudadanos espacios libres de calidad), deben adoptarse las máximas garantías jurídicas. Entre ellas, el citado artículo 50 del Texto Refundido de 1976 —leído a la luz del conjunto del ordenamiento vigente- exige que la aprobación definitiva de la reforma cuente con el informe favorable del Consejo de Estado o del órgano consultivo autonómico correspondiente, si lo hubiera. Informe que será vinculante si es contrario a la modificación de la zona verde que se pretende alterar, y meramente habilitante si es favorable a la modificación pretendida.

Los consejos consultivos intervienen en este tipo de expedientes administrativos como garantía del mantenimiento (en el sentido de superficie y calidad del suelo) de las zonas verdes y los espacios libres públicos fijados en el planeamiento inicial. Dicho con otras palabras, los consejos consultivos, en la defensa del principio de la «intangibilidad» de las zonas verdes, no sólo han de examinar el tema de su extensión superficial (cuando se pretenda su modificación), sino también, y tal vez prioritariamente, el de su funcionalidad para el uso, goce y disfrute de los ciudadanos. En este sentido, no es frecuente que los Ayuntamientos intenten cambiar una zona verde por otra con menos metros, pero es bastante frecuente que la calidad de la nueva zona propuesta sea muy inferior a la que pretenden eliminar. Lo que en estos casos obliga a una intervención decidida del consejo consultivo para poner freno a las tentaciones leviatánicas del poder municipal.

Se trata —como ha señalado el Tribunal Supremo (STS de 2 de febrero de 1981) - de proteger las zonas verdes con el máximo rigor, no en el sentido de mantenerlas a perpetuidad, puesto que pueden presentarse ocasiones en las que sea necesario su modificación o incluso su supresión para atender a objetivos aún más apremiantes, pero ello se condiciona en la Ley al cumplimiento de rigurosos requisitos cuya observancia es ineludible. La importancia de los intereses en juego justifica que los consejos consultivos autonómicos centren su atención en la salvaguardia del interés público, que exige la presencia en los ordenamientos urbanísticos de terrenos destinados a finalidades colectivas.

\subsection{Segregación de municipios}

La intervención de los consejos consultivos autonómicos en la alteración de los términos municipales (que es una competencia trans- 
ferida a todas las Comunidades Autónomas) viene impuesta por los artículos 9.2, 10.5 y 11.4 del Reglamento de Población y Demarcación Territorial de las Entidades Locales (aprobado por el Real Decreto 1.690/1986, de 11 de julio). De acuerdo con dichos preceptos, el expediente de alteración de los límites territoriales (por incorporación de uno o más municipios a otro u otros limítrofes, por fusión de dos o más municipios limítrofes, por segregación de parte del territorio de uno o varios municipios para constituir otro independiente, o por segregación de parte del territorio de un municipio para agregarla a otro limítrofe) debe remitirse para dictamen al Consejo de Estado o al consejo consultivo autonómico, si existiese. Simultáneamente a la petición de dicho dictamen, se dará conocimiento a la Administración del Estado de las características y datos principales del expediente que lo motiva.

Los consejos consultivos, siguiendo la doctrina marcada por la Sala Tercera del Tribunal Supremo (ver, por todas, las Sentencias de 10 de junio de 1999, 5 de octubre de 2000, 30 de octubre de 2000 y 22 de enero de 2001), deben dirigir su atención a evitar la discrecionalidad de la Administración con poder decisorio en esta materia. Es cierto que ésta puede optar «entre soluciones equivalentes, desde la perspectiva de su legalidad, en función de la oportunidad o de la conveniencia respecto del bien común o del interés general», pero "tal holgura de movimientos no puede conducir nunca a la arbitrariedad y encuentra su límite en los elementos reglados del acto que han de ser respetados" (STS de 30 de octubre de 2000). Este debe ser el parámetro en la actuación de los órganos consultivos autonómicos, que han de ser extraordinariamente "exigentes en el requisito de motivación del acto administrativo, debiendo quedar clara cual es la finalidad perseguida con él y que la misma potencialmente puede lograrse mediante los mecanismos puestos en movimiento" (STS de 10 de junio de 1999).

Por su parte, el Consejo de Estado, en su Dictamen número 51.697, ha señalado "que el interés público no es sólo de la comunidad que pretende la segregación y erigirse en municipio independiente. Es también el interés de la entidad local preexistente y aún puede afirmarse que no se agota en el interés local el interés público" (en la misma línea pueden verse, entre otros, sus dictámenes 37/1993 y 50/1993). Sin embargo, como precisa certeramente la Comisión Jurídica Asesora del Gobierno de Aragón (Dictamen 41/1997), "si bien parece claro que no existe un derecho autónomo ni subjetivo a constituirse en municipio", tampoco se puede negar sin fundamento este derecho a un núcleo de población que reúne las condiciones legales exigidas («sin que el municipio matriz ostente un derecho de veto inmotivado sobre esta decisión»). 


\subsection{Recurso extraordinario de revisión}

De acuerdo el primer apartado del artículo 118 de la LRJAP-PAC, contra los actos firmes en vía administrativa podrá interponerse el recurso extraordinario de revisión ante el órgano administrativo que los dictó, que también será el competente para su resolución, cuando concurran una serie de causas tasadas que establece este mismo precepto. En concreto, los motivos que lo fundamentan son los siguientes: que al dictarlos se hubiera incurrido en error de hecho (que resulte de los propios documentos incorporados al expediente); que aparezcan documentos de valor esencial para la resolución del asunto que, aunque sean posteriores, evidencien el error de la resolución recurrida; que en la resolución hayan influido esencialmente documentos o testimonios declarados falsos por sentencia judicial firme (anterior o posterior a aquella resolución); o que la resolución se hubiera dictado como consecuencia de prevaricación, cohecho, violencia, maquinación fraudulenta u otra conducta punible, y se haya declarado así por sentencia judicial firme.

Por su parte, el artículo 119.1 de la misma Ley, tras la reforma introducida por la Ley 4/1999 (de 13 de enero), dispone que «el órgano competente para la resolución del recurso podrá acordar motivadamente la inadmisión a trámite, sin necesidad de recabar dictamen del Consejo de Estado u órgano consultivo de la Comunidad Autónoma, cuando el mismo no se funde en alguna de las causas previstas en el apartado 1 del artículo anterior o en el supuesto de que se hubiesen desestimado en cuanto al fondo otros recursos sustancialmente iguales". Este artículo da a entender, a contrario sensu, que en los otros casos, sí será necesaria la intervención del órgano consultivo. De hecho, el art. 22.9 de la Ley Orgánica del Consejo de Estado así lo exige expresamente.

De esta regulación legal resulta que el recurso de revisión es, como dice su propio nomen iuris, extraordinario, pues sólo procede contra actos firmes en vía administrativa y por motivos rigurosamente tasados. De ahí que no pueda convertirse en un cauce para recurrir un acto por cualquier causa, pues ello desvirtuaría su carácter excepcional. Como señala el Dictamen 14/2002 del Consejo de Navarra, los consejos consultivos han de vigilar que la interpretación de los motivos de admisión sea estricta, "para evitar que se convierta en vía ordinaria de impugnar los actos administrativos transcurridos los plazos al efecto establecidos». En la misma línea argumental, el Dictamen 25/2003 del Consejo Consultivo de Castilla-La Mancha afirma que el recurso extraordinario de revisión supone que, frente a la generalidad de los recursos, única- 
mente podrá interponerse en los supuestos previstos de manera expresa por la Ley y en base a las circunstancias fijadas de modo taxativo en la misma. De ello se deriva necesariamente la inviabilidad de que, con ocasión de su interposición, se susciten nuevas cuestiones propias de los recursos de carácter ordinario.

Title:

"Autonomous consultative bodies and local government".

\title{
Summary:
}

1. THE ADVISING FUNCTION OF THE AUTONOMOUS CONSULTATIVE BODIES: ORIGIN, ESSENCE AND MEANING. 2. THE POWERS OF THE AUTONOMOUS CONSULTATIVE BODIES CONCERNING LOCAL GOVERNMENT: 2.1. Introduction. 2.2. Conflicts of jurisdiction before the Constitutional Court. 2.3. Damage claims against local bodies. 2.4. Self-revision of local decisions. 2.5. Interpretation, modification, termination and nullification of contracts agreed to by local bodies. 2.6. City planning modifications concerning green areas. 2.7. Segregation of municipalities. 2.8. Extraordinary appeal.

\section{Key words:}

- Consultative function.

- Autonomous consultative bodies.

- Local government.

\begin{abstract}
:
Prior to taking a number of especially important decisions, both the government and the public administrations need the expert legal advice of an independent consultative body (the Council of State or its autonomous counterparts). Since in most cases that legal opinion is not mandatory, the executive body may not follow it. However, the government or the public administration must set out the reasons of its dissent, which might amount to a legal discredit.

The functions of the autonomous consultative bodies concerning local government are the topic of this work. A first approach will lead us to deal briefly with the origin, essence and meaning of the autonomous consultative bodies.
\end{abstract}


Fifteen autonomous consultative bodies have been created so far. A quick glimpse at their powers leads to the conclusion that local bodies need their legal advice in this matters: conflicts of jurisdiction before the Constitutional Court against acts that allegedly violate local autonomy (the advice must be sought within three months after the publication of the act); damage claims against local bodies (in a number of cases, the advice is mandatory only if the claim reaches a certain amount); self-revision of local decisions (to attain it, the consultative body must agree); interpretation, modification, termination and nullification of contracts agreed to by local bodies (either when the contractor disagrees or the modified amount is higher than the previous one plus a twenty percent); city planning modifications concerning green areas; segregation of municipalities; extraordinary appeal (consultative bodies must preserve the strict interpretation of the grounds on which the appeal is taken into consideration). 